\title{
Assessing the effects of hybridization and precipitation on invasive weed demography using strength of selection on vital rates
}

\author{
Zachary Teitel ${ }^{1,2}$, Agnieszka Klimowski $^{1,3}$ and Lesley G. Campbell ${ }^{*}$
}

\begin{abstract}
Background: As global climate change transforms average temperature and rainfall, species distributions may meet, increasing the potential for hybridization and altering individual fitness and population growth. Altered rainfall specifically may shift the strength and direction of selection, also manipulating population trajectories. Here, we investigated the role of interspecific hybridization and selection imposed by rainfall on the evolution of weedy life-history in non-hybrid (Raphanus raphanistrum) and hybrid ( $R$. raphanistrum $\times R$. sativus) populations using a life table response experiment.
\end{abstract}

Results: In documenting long-term population dynamics, we determined intrinsic $(r)$ and asymptotic $(\lambda)$ population growth rates and sensitivities, a measure of selection imposed on demographic rates. Hybrid populations experienced 8.7-10.3 times stronger selection than wild populations for increased seedling survival. Whereas crop populations generally exhibit little dormancy and wild populations often exhibit dormancy, non-hybrid populations experienced $10 \%$ stronger selection than hybrid populations for exhibiting seed dormancy. Selection on survival-toflowering in wild, not hybrid, populations declined marginally with increasing soil moisture. Hybrid populations exhibited greater $r$, but not $\lambda$, than wild populations regardless of moisture environment. In general, fecundity contributed most to differences in $\lambda$ but fecundity only contributed positively to hybrid $\lambda$ relative to wild $\lambda$ when precipitation was altered (either higher or lower than control) and not under control watering conditions.

Conclusions: Selection on key demographic traits may not change dramatically in response to rainfall, and hybridization may more strongly influence the demography of these weedy species than rainfall. If hybrid populations can respond to selection for increased dormancy, this may make it more difficult to deplete weed seed banks and increase the persistence of crop genes in weed populations.

Keywords: (3-10): Demography, Experimental evolution, Gene flow, Global climate change, Life Table Response Experiment, Raphanus raphanistrum, Raphanus sativus, Rain-out shelter

\section{Background}

Hybridization between crops and their wild and weedy relatives instantaneously changes the genetic composition of weed populations [1] and thus may influence phenotypic evolution and success of weedy or invasive populations [2-4]. Crop-wild hybridization may result in either

\footnotetext{
* Correspondence: lesley.g.campbell@ryerson.ca

${ }^{1}$ Department of Chemistry and Biology, Ryerson University, 350 Victoria

Street, Toronto, ON M5B 2K3, Canada

Full list of author information is available at the end of the article
}

the transfer of adaptive, crop alleles to weed populations [5] or the generation of unique hybrid phenotypes via transgressive segregation [6]. In either case, crop-wild hybrid weed populations may exhibit significantly different phenotypes relative to ancestral wild and/or weedy populations [7-9]. The fitness advantage of these new weedy phenotypes is often context dependent $[10,11]$. For instance, under stressful agricultural conditions that accompany the application of herbicides or weed-competition gradients, sometimes weed fitness can be enhanced by the 
acquisition of crop traits. In contrast, under less selective environments, the acquisition of crop genes may reduce weed fitness [12, 13]. Furthermore, traits that are beneficial for weeds in agricultural contexts can vary regionally due to the arrangement of genetic variation in geographic selection mosaics [14]. Therefore, evaluating the ecological consequences of crop-wild hybridization in one environmental context (vs. many) may underor overestimate the potential success of hybrid weed populations $[3,15]$.

If fitness advantages of advanced-generation hybrids are context-dependent, then one might predict that environmental gradients should be important influences on population demography [16]. For instance, under some stressful conditions (e.g., herbicide application or competition), weed fitness can be boosted by acquiring crop traits $[12,13]$. Where broad environmental clines are important for defining population dynamics, changes to these climatic conditions may alter the magnitude and direction of selection acting on plants [17] and thus impact population growth. However, selection changing with environmental gradients is context-dependent $[18,19]$, and population dynamics are also influenced by the relative frequency of genotypes within that population $[20,21]$.

Providing that abiotic selection pressures vary across environmental clines $[19,22]$, the persistence of cropwild hybrid populations may be determined by the strength of selection acting on fitness-correlated traits. One such fitness-correlated trait is drought tolerance, a selection target that varies among environments with different precipitation conditions [23]. In drought conditions, water loss is highly detrimental to fitness, so drought tolerance should be strongly favoured [24]. As well, crop plants are thought to have better drought tolerance than their wild relatives $[25,26]$, so altered precipitation patterns by human-mediated global climate change may have a substantial effect on selection between wild and hybrid weeds $[27,28]$. In agricultural plant communities, where crop and compatible weedy relatives coexist, we may expect different life-history responses to identical environmental cues [29]. Contrasting strategies of resource allocation in high- and low-stress environments may be driven by adaptive physiological and morphological differences between wild and crop plants [30, 31]. For example, droughtadapted plants can minimize water loss in drought conditions by closing their stomata, though this will convert fewer carbon resources [24]. If crop plants hybridize with wild relatives, the resulting crop-wild hybrid offspring could exhibit a combination of alternate life-history strategies, and potentially succeed in environments that exclude or minimize the weediness of the wild parent [32].
Geographic and temporally shifting climatic conditions can affect plant phenology and fecundity, key fitnessrelated traits [33]. In particular, variation in precipitation patterns may have dramatic consequences for the subsequent fitness of crop-wild hybrids. Climate models predict punctuated and extreme rainfall over terrestrial regions, including more severe drought and flooding events [34]. Changing climate may impact agricultural ecosystems in particular, where farmers rely on high rates of germination and survival, and high fecundities in cultivated species while attempting to minimize these same life-history traits in weedy competitors.

Ecological risk-assessments of weeds derived from cropto-wild hybridization have largely based their conclusions on one or a few stages of a plant's life cycle (e.g., female fecundity), which may not accurately predict population dynamics [35]. In fact, assessing seed production alone would have supported incorrect conclusions relative to complete life-history data in crop-wild systems of Lactuca and Raphanus, or above- and below-ground biomass of Brasica rapa and B. napus hybrids [2, 13, 36]. If crop-wild hybridization alters weed life history [e.g., [9]], these new life histories may affect vital rate contributions to population growth and alter the effectiveness of weed management practices [36]. In summary, there is little information that projects the impact of crop-wild hybridization events combined with extreme rainfall or drought events on the life-history dynamics of invasive weed populations.

To assess the impact of crop-wild hybridization and projected environmental variation (specifically water availability) on the population dynamics of nascent cropwild hybrid populations, we used a Life Table Response Experiment (LTRE). A LTRE decomposes a cumulative dependent variable into its contributing metrics that compose that dependent variable. The population dynamics of weedy phenotypes are dictated by multiple interacting components of fitness that may be best captured by a demographic modeling approach. Transitions among key life-history stages (e.g., rates of germination, survival and reproduction) are closely associated with individual fitness and collectively contribute to population growth, often measured as an asymptotic rate of population growth ( $\lambda$ ) [37]. For example, fecundity strongly contributes to $\lambda$ in the crop-wild Raphanus complex $[4,38]$. A LTRE tests for the consequences of experimental manipulations on a population's growth, using demographic transitions (or vital rates) as well as assessing the sensitivity of the model to proportional conversions between stages $[39,40]$. Because sensitivities reflect a functional correlation with multiple components of fitness, they can be interpreted as the strength of selection acting on a particular life-history trait $[37,41]$. 
A central challenge in research of annual, agricultural weeds is to identify how their success can be curbed by control measures. Weeds may be considered difficult to control or invasive when they exhibit rapid population growth, longer population persistence (due to denser populations, seed banks or aggressive competitive abilities), and a greater ability to disperse or found new populations (framework described in [38]). When selection is applied to biological populations, we expect population size to decline and a lowered probability of long-term persistence [42-44]. Alternatively, although strong selection may reduce population size, the resulting population may be at a higher fitness peak and thus should persist for a longer period of time $[45,46]$. Here, we focus on assessing the relationship between natural selection on wild versus hybrid genotypes grown under a range of moisture gradients and their problematic persistence.

To test the prediction that segregating crop-wild hybrid populations will experience stronger selection and hence reduced population size, relative to non-hybrid weed populations, we compared the population growth rates and the strength of selection on vital rates of wild versus cropwild hybrid Raphanus populations across an experimental moisture gradient $[37,47,48]$. Through our experimental demography approach, we explore how selection on weedy life histories can be altered by moisture gradients and anticipate weed evolution in variable climates.

\section{Methods}

\section{Study species}

To explore the role of hybridization and soil moisture application in weed invasion, we used the Raphanus (Brassicaceae) crop-wild complex. Here, the term 'biotype' subsequently refers to the taxa: wild $R$. raphanistrum biotype, crop $R$. sativus biotype, and the hybrid $R$. raphanistrum x $R$. sativus biotypes. All three biotypes are self-incompatible and insect-pollinated [49]. Crop and wild Raphanus biotypes can be distinguished by petal colour, a simply inherited Mendelian trait, where the white-petal allele (a crop trait seen in hybrids) is dominant and the yellow-petal allele (a wild trait) is recessive [50]. Therefore, $\mathrm{F}_{1}$ crop-wild hybrids are $100 \%$ white flowered and advanced generations often exhibit mixtures of white and yellow flowered plants, depending upon the hybridization rate [3].

These annual plants have a sequential life cycle, subject to mortality at any stage. Further, $R$. raphanistrum, with a long-lived seed bank, high genetic variability, and early emergence after soil disturbance, is considered a weed in more than 45 crop systems and 65 countries [51], so changes to its spread and persistence could impact a large diversity of agricultural cropping systems. The wild biotype, $R$. raphanistrum exhibits delayed germination with a long seasonal range but reaches reproductive maturity earlier than the crop biotype, $R$. sativus, which germinates synchronously within a few days of planting and flowers late in the season $[9,49]$. These differences in key lifehistory traits may have important implications for the weediness of their hybrid offspring. Hybrid biotypes can benefit from inheriting germination and flowering times from crop biotypes within agricultural environments.

\section{Study site}

We conducted this study at the Koffler Scientific Reserve (KSR) at Joker's Hill, King City, ON Canada (440' N; 79 $3^{\prime}$ $\mathrm{W}, 285 \mathrm{~m}$ asl) for field experiments in abandoned agricultural fields from 2011-2013, involving $F_{1}$ to $F_{3}$ generation offspring. Here, the growing seasons during which we conducted our field experiments spanned the period of May 24th - October 25th.

\section{Establishment of replicated populations}

During the summer of 2010, 36 populations of nine $F_{0}$ cultivated and nine $F_{0}$ wild plants were grown in field plots in Columbus, $\mathrm{OH}$ and exposed to one of four watering treatments (no rain, double rain and two types of control plots), as described in [52] to create wild and hybrid offspring at naturally occurring rates. To determine if crop-wild hybrid radish populations experience stronger selection on demographic traits than wild radish, in 2011, we established 24 replicated populations (plots) of wild or $\mathrm{F}_{1}$ crop-wild hybrid radish seeds. First generation $\left(\mathrm{F}_{1}\right)$ seeds were collected from $\mathrm{F}_{0}$ wild radish that had either mated with $\mathrm{F}_{0}$ wild radish or had mated with $\mathrm{F}_{0}$ crop radish, respectively. Seeds were collected only from wild radish mothers for experimental use as the wild or crop-wild hybrid $F_{1}$ generation in 2011 to allow us to accurately describe the biotype of offspring. Plots were separated by $>40 \mathrm{~m}$ to prevent gene flow. Due to environmental variation across KSR, we used a randomized complete block design with three blocks, each including one plot per watering treatment per biotype. Plots were tilled by May 15th, annually. These experimental populations have been previously described [53].

Two weeks after germinating in a greenhouse, 117 randomly selected $F_{1}$ seedlings were transplanted into plots, $15 \mathrm{~cm}$ apart. As plants flowered, petal colour was noted; wild plants possessed yellow petals and hybrid plants possessed white petals. Plots were randomly assigned a biotype treatment; any plant representing the "wrong" biotype relative to the assigned biotype was removed upon detection. This created the opportunity for a very small amount of gene flow to occur (detected in one "wild" plot in 2012). Flowering plants fruited and senesced naturally, producing $F_{2}$ in 2012 and $G_{3}$ in 2013 (individuals in $\mathrm{G}_{3}$ could have been $\mathrm{F}_{2}$ or $\mathrm{F}_{3}$ genotypes, due to seed dormancy). Annually, seeds from a 
representative group of plants (maximum 30 individuals) were collected to assess individual fecundity; otherwise seeds dispersed naturally.

\section{Experimental treatments}

To manipulate soil moisture, we imposed four watering treatments from July 1-August 31, 2011, June 4 - August 31, 2012 and June 10 - September 6, 2013. Rainout shelter roofs were made from translucent plastic attached to $7.44 \mathrm{~m}^{2}$ wooden frames elevated $1.2 \mathrm{~m}$ above ground and slightly sloped northwest. Intercepted precipitation was collected in rain barrels and we applied watering treatments within two days of collection. Only 15 of 24 plots were used to measure $\lambda$ due to low seed production in 2011 (replication described below). We hand weeded plots to minimize interspecific competition.

We administered the following four watering treatments: 1) Control Unsheltered (CU), where rainwater fell naturally on plots (analyses of $r: 3$ wild, 3 hybrid plots); 2) Control Shelter (CS), where plots assessed effects of rainout shelters, and collected rainwater was reapplied to the plot (analyses of $r$ : 3 wild, three hybrid plots; analyses of $\lambda$ : 3 wild, 2 hybrid plots); 3) No Rain (LR), where plots assessed effects of reduced precipitation, so collected rainwater was withheld (analyses of $r: 3$ wild, 3 hybrid plots; analyses of $\lambda: 1$ wild, 3 hybrid plots); 4) Double Rain (DR), where plots assessed effects of increased precipitation, thus DR plots received the normal rainfall plus rainwater collected from LR plots within the same block (analyses of $r: 3$ wild, 3 hybrid plots; analyses of $\lambda: 3$ wild, 3 hybrid plots). The LR and DR treatments were designed to simulate extreme precipitation patterns that are projected to result from climate change [34]. Experimental watering treatments significantly and predictably altered the average volumetric moisture content in both years [53]. Control sheltered plots had significantly lower soil moisture than double rain plots and significantly higher soil moisture than no rain plots.

\section{Annual surveys of replicated populations}

Whereas $\lambda$ describes the proportional change in population size in discrete time, the exponential growth of weed populations may also be described by the intrinsic rate of increase, $r$. To estimate $r$, annual counts of flowering and non-flowering individuals were conducted in 2012 and 2013. Using abundance estimates of each whole plot in 2011 and within subplots (see subplot details below) in 2012 and 2013, we calculated plant density (number of individuals $/ \mathrm{cm}^{2}$ ) to determine how population growth rate $(r)$ changed through time. Instantaneous population growth rate $(r)$ was calculated as the difference in natural log transformed population size density $(N)$ for year and year $_{t-1}$. We ran a mixedmodel ANOVA to determine whether biotype, watering treatment, or their interaction or block resulted in significant changes in $r$.

\section{Weekly surveys of replicated populations}

Annually, we established a $1 \mathrm{~m}^{2}$ subplot in the centre of each plot, within 16 days of tilling. We intended to follow $\sim 50$ plants per subplot, but plant density varied between subplots. When more than 50 plants germinated within a subplot, we methodically reduced subplot size until it contained $\sim 50$ plants.

Weekly censuses monitored four key life-history stages of seed, cotyledon, non-flowering adult and flowering adult that described five vital rates of seed germination, seed dormancy, survival-to-non-flowering adult, survivalto-flowering adult and fecundity (as in $[38,53]$ ). Seed dormancy was estimated from results of a companion seed burial experiment [53], such that dormancy vital rates were weighted by dormancy rates of their corresponding plot and removal date, adjusted for population size. Mortality could occur at each stage and is reflected in the proportion of individuals that survive to the next lifehistory stage. A plant that went unrecorded for $>$ two weeks was presumed dead. If a plant was rediscovered, and the plant either did or did not mature from the last known entry, we filled in the missing week(s) with the last known status. Data are recorded in [54].

Plants were harvested as they senesced or at the last weekly census, after the first frost when there was no new fruit development (Z. Teitel, pers. obs.). Above-ground biomass was collected in paper bags and dried in an oven for $c a$. seven days at $30{ }^{\circ} \mathrm{C}$. For 30 randomly selected, reproductive plants per sub-plot (or all plants when population size $\leq 30$ reproductive plants), we counted the number of fruits per plant. Number of seeds per fruit was assessed by counting locules in a silique for 10 randomly chosen fruits per plant. To estimate the number of seeds per plant, we multiplied the average number of seeds per fruit by the number of fruits.

\section{Analysis of population demography}

We used a fixed-effect life table response experiment (LTRE; [37]) to compare lambda ( $\lambda$ ) of each experimental population each year (48 constructed matrices; e.g., wild double-rain replicate 1 , hybrid no-rain replicate 2 , etc.) as a linear function of biotype $(g)$, watering treatment $(w)$, and their interaction $(g w)$ : $-\lambda^{g w}=\lambda^{(. .)}+\alpha^{g}+\beta^{w}+\alpha \beta^{g w}$ where $\alpha^{g}$ is the effect of the $g^{\text {th }}$ level of the biotype, $\beta^{w}$ is the effect of the $w^{\text {th }}$ level of the watering treatment, and $\alpha \beta^{g w}$ is the interaction of the $g^{\text {th }}$ biotype and $w^{\text {th }}$ watering treatment, measured relative to the projected growth rate of a reference matrix ${ }^{(. .)}$.

To obtain the treatment matrices, we first averaged all replicates of matrices belonging to a given treatment combination (e.g., the transition frequencies of double-rain 
replicates 1,2, and 3 for wild and hybrid populations were averaged) $[4,55]$. We then averaged common treatment groups of these matrices to give us mean representative matrices for a given treatment (mean wild type, mean double-rain, etc.). We estimated treatment effects as:

$$
\begin{aligned}
& \alpha^{g}=\lambda^{g \cdot}-\lambda \cdot \approx \sum\left[\alpha_{i j}^{g}-\alpha_{i j}^{\cdot \cdot}\right] \cdot\left(\delta \lambda / \delta \alpha_{i j}\right) \mid\left[A^{g \cdot}+A^{\cdot \cdot]}\right] / 2 \\
& \beta^{w}=\lambda^{\cdot w}-\lambda \cdot \approx \sum\left[\alpha_{i j}^{\cdot w}-\alpha_{i j}^{\cdot \cdot}\right] \cdot\left(\delta \lambda / \delta \alpha_{i j}\right) \mid\left[A^{\cdot w}+A^{\cdot \cdot]}\right] / 2 \\
& \alpha \beta^{g w}=\lambda^{g w}-\lambda^{\cdots}-\alpha^{g}-\beta^{w} \cdot \approx \sum\left[\alpha_{i j}^{g w}-\alpha_{i j}^{\prime}\right] \cdot\left(\delta \lambda / \delta \alpha_{i j}\right) \mid \frac{\left[A^{g w}+A^{*}\right]}{2}-\alpha^{g}-\beta^{w}
\end{aligned}
$$

where we obtained elasticities (as described in [42]) and sensitivities $\left(\delta \lambda / \delta a_{i j}\right)$ from the relationship $\delta \lambda / \delta a_{i j}=v_{i} w_{j} /$ $\langle w, v\rangle$ where $a_{i j}$ is a matrix element in the $i^{t h}$ row and $j^{t h}$ column, and $v$ and $w$ are the right and left eigenvectors of the matrix and evaluated the sensitivities, halfway between the reference and treatment matrices [37]. Sensitivities describe how $\lambda$ changes in response to changes in matrix elements, and elasticies are standardized sensitivities. We obtained treatment matrices (e.g., $\mathrm{A}^{\mathrm{g}}, \mathrm{A}^{\cdot \mathrm{w}}$ ) by pooling data across all levels of the other treatments. Finally, the contributions were calculated by weighting the differences in vital rates by their sensitivities. Therefore, the above equations describe both observed variation in matrix elements and the sensitivity of population growth to variation in those elements that influence the effect of treatments on population growth. A particular matrix element $a_{i j}$ may contribute little to variation in $\lambda$ in cases when $a_{i j}$ was invariant among treatment classes and/or when $\lambda$ was insensitive to variation in $a_{i j}$. Additionally, $a_{i j}$ may contribute to little variation in $\lambda$ even if $\lambda$ was highly sensitive to the element if the vital rate did not differ among treatments. In alternate scenarios, even small amounts of variation in $a_{i j}$ may drive variation in $\lambda$ when there are consistent differences among treatments and when $\lambda$ is highly sensitive to that matrix element. Matrix algebra and analyses were performed using MATLAB (v.2012a; The Mathworks, Inc., Natick, Massachusetts, U.S.A).

To determine how biotype and environment contribute to $\lambda$, we conducted a Type III ANOVA in which biotype, watering treatment, block, and their interaction were fixed effects for the response variable of $\lambda$. We analyzed each year separately because the model did not have enough degrees of freedom for this factor to be included. To determine how biotype and environment affect the sensitivity of $\lambda$ to vital rates (i.e., the selection gradient), we conducted a repeated measures ANOVA in which biotype and watering treatment were between-subject effects, and year, biotype and watering treatment were within-subject effects. In both models, block was not a significant effect in the model and was removed. We used SPSS Statistics 21 (2012; SPSS Inc., Chicago Illinois USA) for all analyses.

\section{Results}

The strength of selection on weed vital rates

Selection, measured as the sensitivity of $\lambda$ to proportional changes in vital rates, varied significantly with year, soil moisture, and biotype for at least one vital rate (Table 1). Therefore, we explored the effect of soil moisture and biotype for each year independently (Table 1b, c). Selection for survival-to-flowering adult was about 8.7 times stronger on hybrid relative to wild biotypes in 2012 (Table 1b, Fig. 1) and 10.3 times stronger in 2013 (Table 1c, Fig. 1a). Selection for dormancy was $\sim 10 \%$ stronger on wild relative to hybrid biotypes, in 2012 (Table 1b) and only marginally stronger in 2013 (Table 1c, Fig. 1b). The strength of fecundity selection differed significantly among years. It is interesting to note that rainfall differed between 2012 and 2013, during the period when Raphanus seeds most frequently germinate (May), such that control plots received twice as much rainfall during that period in 2013 as 2012 (data from KSR research station, summarized in [53]). The strength of selection for survival-to-flowering adult and dormancy did not differ significantly across soil moisture treatments (Table $1 \mathrm{~b}$ and c, Fig. 1). Furthermore, the strength of selection on emergence, survivalto-vegetative rosette or seed production did not differ significantly across biotype or watering treatment in both years (Table $1 \mathrm{~b}$ and $\mathrm{c}$ ).

\section{Population growth rates of wild and crop-wild hybrid populations across a moisture gradient}

From $\mathrm{F}_{1}$ to $\mathrm{F}_{3}$, hybrid populations had higher instantaneous population growth rates $(r)$ than wild populations (Fig. $2 ; F_{1,14}=37.18, P<0.001$ ). In the first generation of population growth $\left(\mathrm{F}_{1}-\mathrm{F}_{2}\right)$, hybrid populations grew four times faster than wild populations (Fig. 2; $F_{1,14}=29.43$, $P<0.0001)$. In the following generation, we saw no significant difference in population growth between biotypes (Fig. 2; $F_{1,14}=1.17, P=0.30$ ). Hybrid populations also had marginally significantly higher asymptotic population growth rates, when measured as $\lambda$, across years (Fig. 3 ).

Across two years, soil moisture did not significantly affect $r$ (Fig. 2; $F_{3,14}=1.52, P=0.25$ ). However, in the first year, LR populations grew slower than populations experiencing other soil moisture treatments (Fig. 2; $\mathrm{F}_{3,14}$ $=6.35, \quad P=0.0061 ; \quad \mathrm{X}_{\mathrm{LR}}=0.3731, \quad \mathrm{X}_{\mathrm{CU}}=2.8956, \quad \mathrm{X}_{\mathrm{CS}}=$ $\left.3.0633, X_{D R}=3.9647\right)$. In contrast, in the second generation, LR populations exhibited significantly higher $r$ than populations grown in other soil moisture treatments (Fig. 2; $F_{3,14}=3.38, P=0.048 ; X_{L R}=2.0522, X_{C U}$ $\left.=-0.4936, X_{C S}=0.4472, X_{D R}=0.04061\right)$. In the first generation, wild populations grown in LR conditions had a significantly lower $r$ than any other biotype-byenvironment combination (Fig. 2; $\mathrm{F}_{3,14}=3.94, P=0.031$ ). However, we saw no significant biotype-by-environment 
Table 1 Repeated measures ANOVA (a) and two-way ANOVA in 2012 (b) and 2013 (c) for biotype, watering treatment and their interaction on strength of selection as measured by sensitivity of $\lambda$ to proportional changes in dormancy, emergence, survival-tonon-flowering adult, survival-to-flowering adult, and fecundity

\begin{tabular}{|c|c|c|c|c|c|}
\hline Source of Variation & Dormancy & Emergence & Survival to Non-flowering Adult & Survival to Flowering Adult & Fecundity \\
\hline \multicolumn{6}{|l|}{ (a) Repeated measures ANOVA: } \\
\hline \multicolumn{6}{|l|}{ Between subject effects: } \\
\hline biotype & $5.622_{1,9}^{*}$ & $6.245_{1,9} 9^{*}$ & $1.556_{1,9}$ & $9.591_{1,9^{*}}$ & $0.018_{1,9}$ \\
\hline watering treatment & $0.461_{2,9}$ & $0.109_{2,9}$ & $0.831_{2,9}$ & $1.289_{2,9}$ & $0.252_{2,9}$ \\
\hline biotype ${ }^{*}$ watering treatment & $.018_{2,9}$ & $0.26_{2,9}$ & $0.922_{2,9}$ & $1.901_{2,9}$ & $0.879_{2,9}$ \\
\hline \multicolumn{6}{|l|}{ Within Subject Effects: } \\
\hline year & $.049_{1,9}$ & $5.067_{1,9}^{+}$ & $13.836_{1,9} 9^{* *}$ & $5.061_{1,9}^{+}$ & $15.955_{1,9}^{* *}$ \\
\hline year*biotype & $.893_{1,9}$ & $0.526_{1,9}$ & $0.8_{1,9}$ & $0.176_{1,9}$ & $0.092_{1,9}$ \\
\hline year*watering treatment & $0.556_{2,9}$ & $1.833_{2,9}$ & $3.379_{2,9}^{+}$ & $5.064_{2,9^{*}}$ & $0.308_{2,9}$ \\
\hline year*biotype*watering treatment & $0.94_{2,9}$ & $0.007_{2,9}$ & $2.986_{2,9}$ & $5.726_{2,9^{*}}$ & $1.571_{2,9}$ \\
\hline \multicolumn{6}{|l|}{ (b) 2012} \\
\hline biotype & $5.806_{1,9^{*}}$ & $4.519_{1,9}^{+}$ & $1.755_{1,9}$ & $7.979_{1,9^{*}}$ & $0.052_{1.9}$ \\
\hline watering treatment & $0.475_{2,9}$ & $0.839_{2,9}$ & $1.666_{2,9}$ & $2.788_{2,9}$ & $0.131_{2,9}$ \\
\hline biotype ${ }^{*}$ watering treatment & $0.17_{2,9}$ & $0.097_{2,9}$ & $1.541_{2,9}$ & $3.796_{2,9}$ & $1.114_{2,9}$ \\
\hline \multicolumn{6}{|l|}{ (c) 2013} \\
\hline biotype & $3.543_{1,9}^{+}$ & $3.406_{1,9}^{+}$ & $1.022_{1,9}$ & $7.388_{1,9^{*}}$ & $0.000_{1,9}$ \\
\hline watering treatment & $0.482_{2,9}$ & $.573_{2,9}$ & $0.202_{2,9}$ & $1.137_{2,9}$ & $0.455_{2,9}$ \\
\hline biotype*watering treatment & $0.185_{2,9}$ & $.295_{2,9}$ & $0.505_{2,9}$ & $1.291_{2,9}$ & $0.839_{2,9}$ \\
\hline
\end{tabular}

interaction across both generations (Fig. 2; $\mathrm{F}_{3,14}=1.25$, $P=0.33$ ), or in the second generation (Fig. $2 ; F_{3,14}=1.37$, $p=0.29$ ). In contrast to the response of $r$ to experimental manipulation, neither watering treatment, nor its interaction with biotype had a significant effect on population growth rate measured as $\lambda$, across years (2012, 2013) (Fig. 3).

\section{The effect of vital rates on population growth across an environmental gradient}

Life-history transitions contributed to changes between hybrid and wild average population growth rates to different degrees and directions (Fig. 4). In general, fecundity contributed most to differences in $\lambda$, followed by germination, then survival-to-flowering adult and finally survival-to-non-flowering adult and seed dormancy (Fig. 4). Differences in germination and survival-to-non-flowering adult between hybrid and wild populations led to higher relative population growth rates in hybrid versus wild populations (Fig. 4). In contrast, differences in dormancy and survival-toflowering adult led to higher relative population growth rates in wild versus hybrid populations (Fig. 4). Finally, fecundity only contributed positively to hybrid $\lambda$ relative to wild $\lambda$ when precipitation was altered and not under the CS treatment (Fig. 4).

\section{Discussion}

Our results contribute to the relatively small body of work that investigates natural selection in field populations of weedy and invasive plants (e.g., [9, 56-58]) and the growing number of studies that use demographic sensitivities to estimate the direction and strength of selection therein $[41,59]$. When a weed colonizes a new location, it may often find itself in a novel environment with selection pressures that are different from its source population. The ability to respond rapidly to these novel selection pressures is perhaps one method in which plants may evolve traits that promote increased weediness (i.e., rapid population growth, longer population persistence, and/or greater ability to found new populations) [60]. Here we documented selection acting on multiple life-history stages of wild and cropwild hybrid Raphanus ssp. Selection analyses revealed that selection strongly favoured both wild and hybrid phenotypes that survived to reproduction in both survey years. In contrast, wild populations experienced stronger selection for dormancy than hybrid populations in 2012 but not 2013, and this difference in selection is perhaps due to differences in water availability, albeit nonexperimentally controlled. Further, selection for juvenile survival to the rosette stage was marginally stronger on hybrid than wild populations and selection was negatively related to soil moisture. Dry spring conditions in 2012 

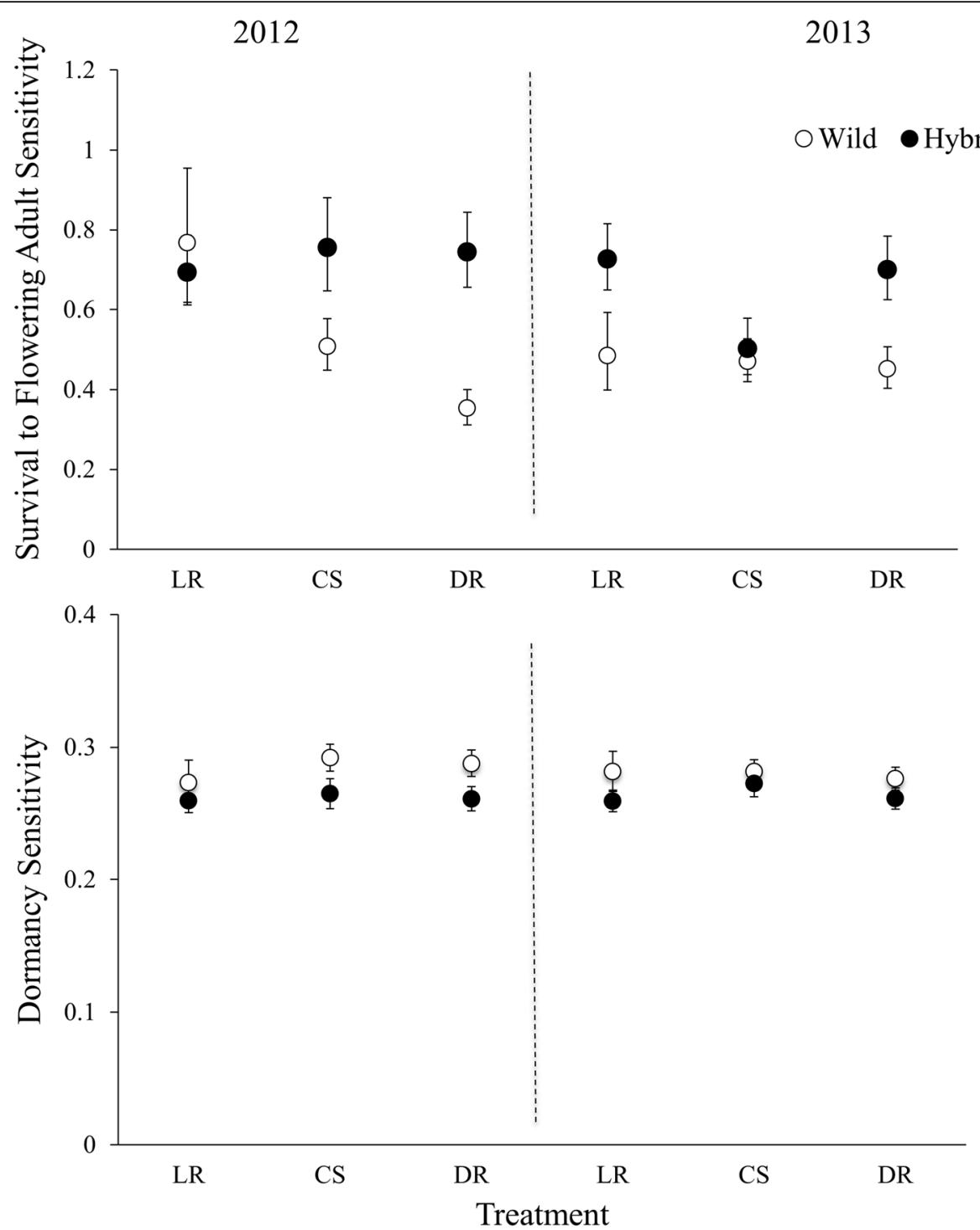

Fig. 1 Top: Back-transformed sensitivities of survival-to-flowering adult, or Bottom: Back-transformed sensitivities of dormancy, between hybrid and wild populations of Raphanus, under three watering treatments [low rain (LR), control shelter (CS), double rain (DR)], grown in King City, ON, in 2012 and 2013. 'Sensitivity' from a vital rate is calculated as the absolute change in $\lambda$ resulting from a change in one of the vital rates

resulted in relatively less population growth (measured as $r$ ) in wild populations only, in direct contrast to the extremely positive growth exhibited by all of other biotype-by-watering treatment combinations. Moreover, fecundity selection acted equally strongly on both biotypes and across watering treatments but was significantly stronger in 2012 relative to 2013. Finally, the differences in population growth among biotypes and watering environments were most influenced by seed production, rather than other life-history stages. Yet, fecundity only contributed positively to higher hybrid population invasiveness relative to wild populations when precipitation was altered and not under the control shelter treatment. These results suggest that weed populations, although predictably most influenced by fecundity selection, may differ in selective environments based on genotype (including the strength and direction of selection on crop-derived traits), or environmental context.

\section{Selection on weeds}

Although we detected only marginally significant differences in $\lambda$ between biotypes, wild and hybrid populations attained similar population growth using alternate life-history strategies. Rates of germination and survivalto-rosette boosted $\lambda$ of hybrid populations, whereas rates of dormancy and survival-to-flowering boosted $\lambda$ of wild populations. These results satisfy our prediction that crop 


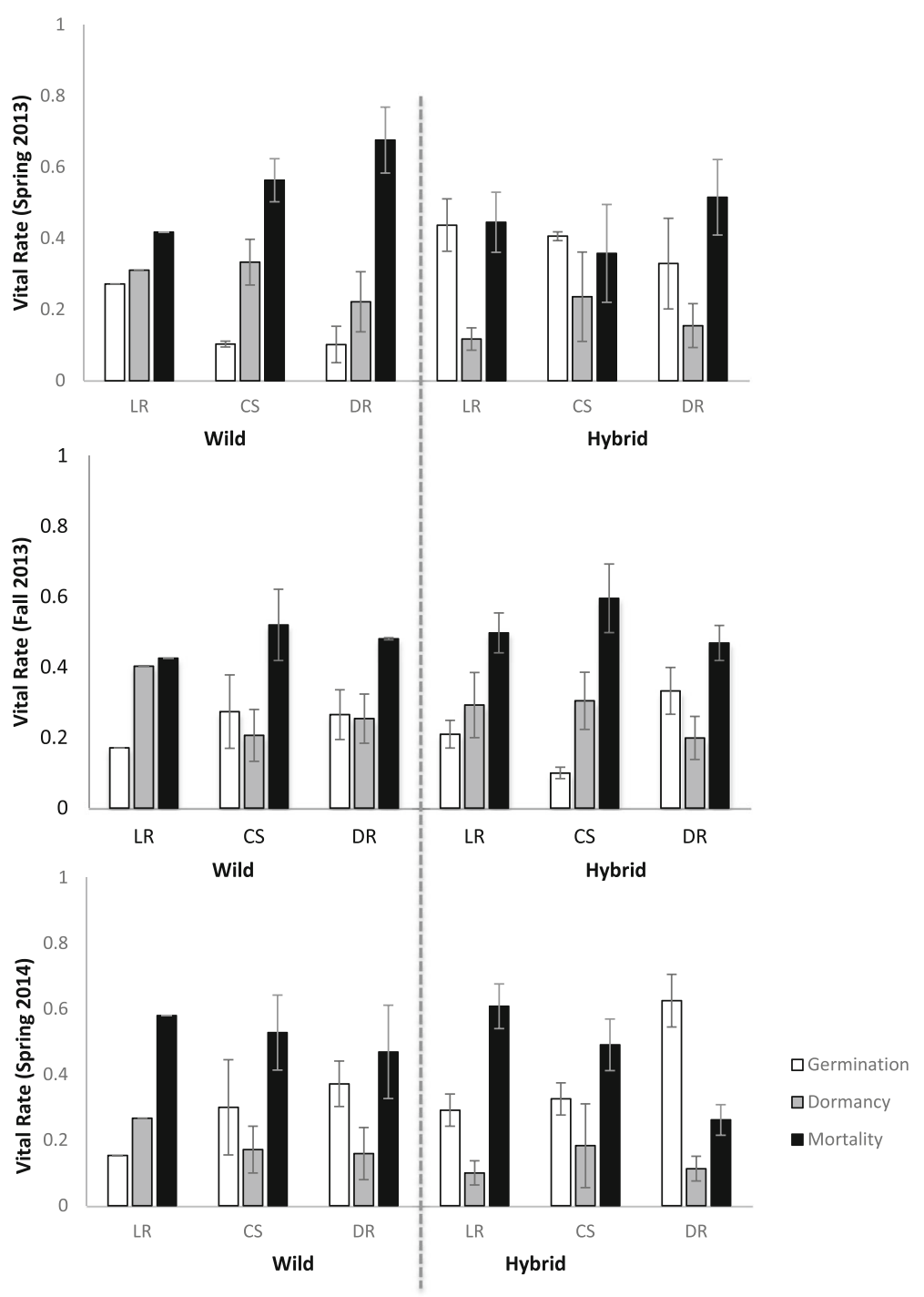

Fig. 2 Comparison of average instantaneous population growth rates ( $r$ ) of wild and crop-wild hybrid populations of Raphanus grown under four watering treatments [low rain (LR), control unsheltered (CU), control shelter (CS), double rain (DR)] in King City, ON (+/- SE) from 2011-2013

seed banks are expected to have synchronous and heightened rates of germination, as well as minimal dormancy, due to continuous selection for domesticated traits [61]. In contrast, wild populations may be subject to a wider range of environmental conditions and can respond to unfavorable growth conditions with prolonged dormancy or staggered emergence [62]. However, the literature surrounding the escape of domesticated, functional traits into weed populations often predicts the opposite result, i.e., that such crop-derived trait are generally expected to be purged from weed populations (e.g., [35, 49]). Selection for an optimal hybrid life-history could result in tradeoffs with other traits. Though data is scarce, there is some evidence that annual weed species suffer from post-emergence mortality in particular [63]. When compared to planted crops, they have far fewer seed reserves to rely on during emergence and seedling establishment [64]. Thus, the relative importance of seed dormancy function is crucial for weed propagation strategy.

Demographic studies that conduct sensitivity analyses, such as ours, often focus on the ecological outcomes and less on the evolutionary interpretations of their findings, making it difficult to place the magnitude of our estimates of selection into context. Conversely, few empirical estimates of strength of selection have been achieved by conducting a life table response experiment [65], and applying sensitivity analyses to measure selection on individual vital rates that describe the entire life history of an organism; those that have used this 


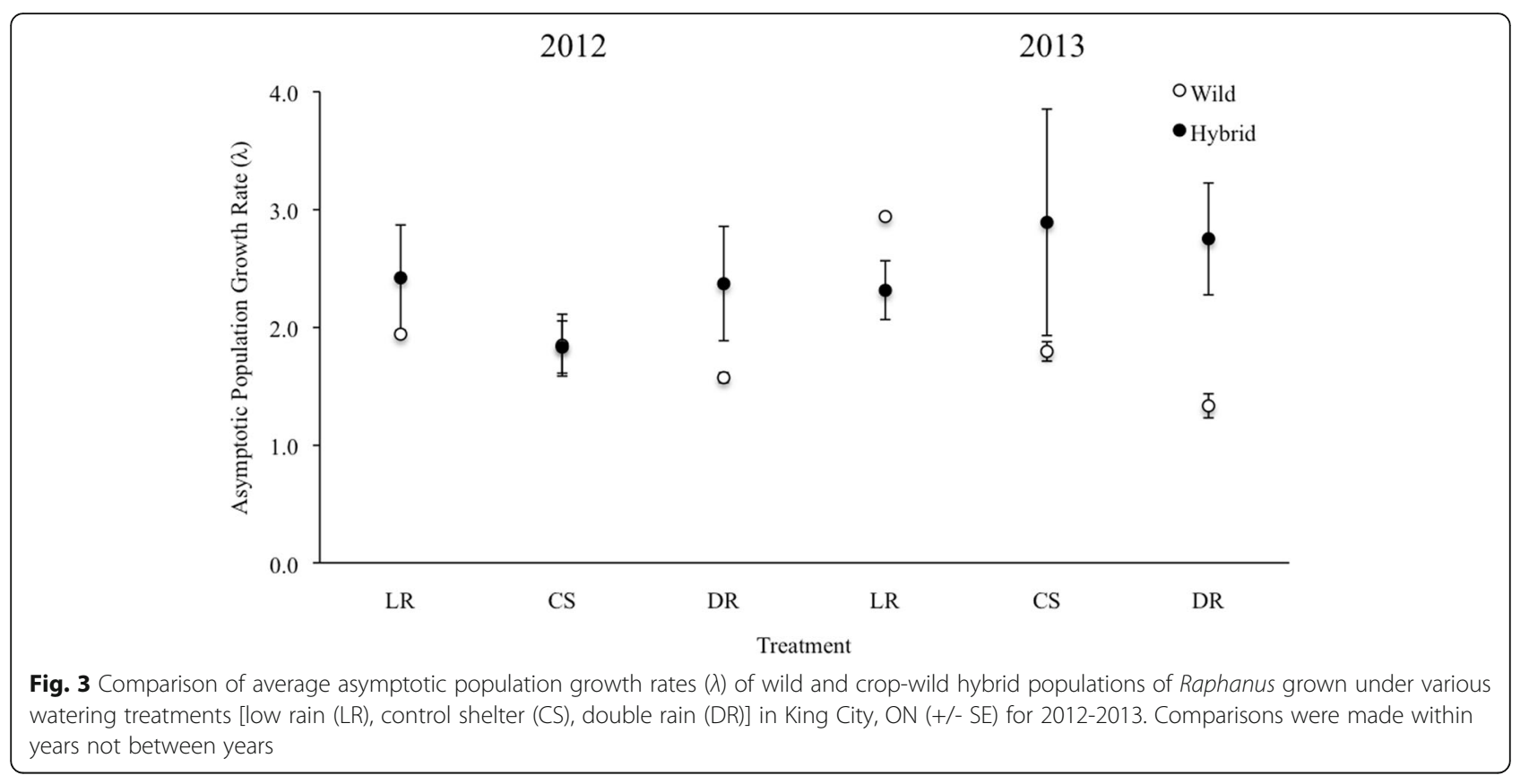

approach tend to address basic biological questions (e.g., [41, 66, 67]). This is despite the considerable value that such prospective analyses have in projecting the spread of invasive weeds $[68,69]$ and predicting how strongly and in what direction $\lambda$ will respond to changes in vital rates due to broad ecological effects [70]. In an earlier comparison of selection on morphological traits in wild and hybrid radish, selection was strongest on number of flowers, a correlate for fecundity selection [9], relative to other morphological traits (and survival was nearly $100 \%$ due to experimental watering). The strength of selection, measured here using sensitivity analysis, appears to be stronger on estimates of demographic transitions than estimates of selection on morphological traits, based on a Lande-Arnold regression approach and short-term correlates of fitness (i.e., total, individual seed production [9]). Though our study supports the conclusion that selection acting on survival may be greater than that on fecundity, the vast literature of published plant demographic matrices [71] has yet to present any conclusive analyses on selection for comparison.

\section{Is Weediness Environmentally Dependent?}

Both biotic and abiotic interactions can alter weedy radish population growth; however, we found limited evidence that soil moisture manipulations dramatically altered long-term population growth of these weeds. Instead, drought conditions resulted in shrinking population sizes (measured as $r$ ) in wild populations in 2012 only, in direct contrast to the positive growth exhibited by all other biotype-by-watering treatment combinations.
Perhaps more intriguingly, we have documented that weeds alter life-history strategies to accomplish the same rate of growth, depending on the environment. For instance, fecundity contributed positively to higher hybrid population invasiveness relative to wild populations only when precipitation was altered and not under the control shelter treatment. This work, where only soil moisture varied, supports previous work that has documented the context dependency of hybrid genotypes across North America, where many environmental variables differed among locations [3, 72]. However, we may have seen differences in $\lambda$ among treatments if there been a larger seed-bank sample size [55] or if the watering treatments were extended to winter months.

Consistent with our results, the literature shows numerous examples of plant demographic parameters sensitively responding to changes in precipitation (e.g., [73, 74]). Whereas drought conditions can cause extensive mortality in weed species over crops, our results did not reveal any effects of the environment or the biotype-by-environment interaction on $\lambda$. This wide environmental tolerance suggests Raphanus spp. can plastically respond to the range of altered moisture conditions we created. Successful plant invaders often need to employ phenotypic plasticity for a wide range of extreme environments [75] and Raphanus appears well to be prepared for both drought and excess moisture conditions.

\section{Demographic analysis - an under-appreciated risk assess- ment tool}

Ultimately, studies of crop-wild hybridization assess whether crop-derived traits will persist in wild or weedy 


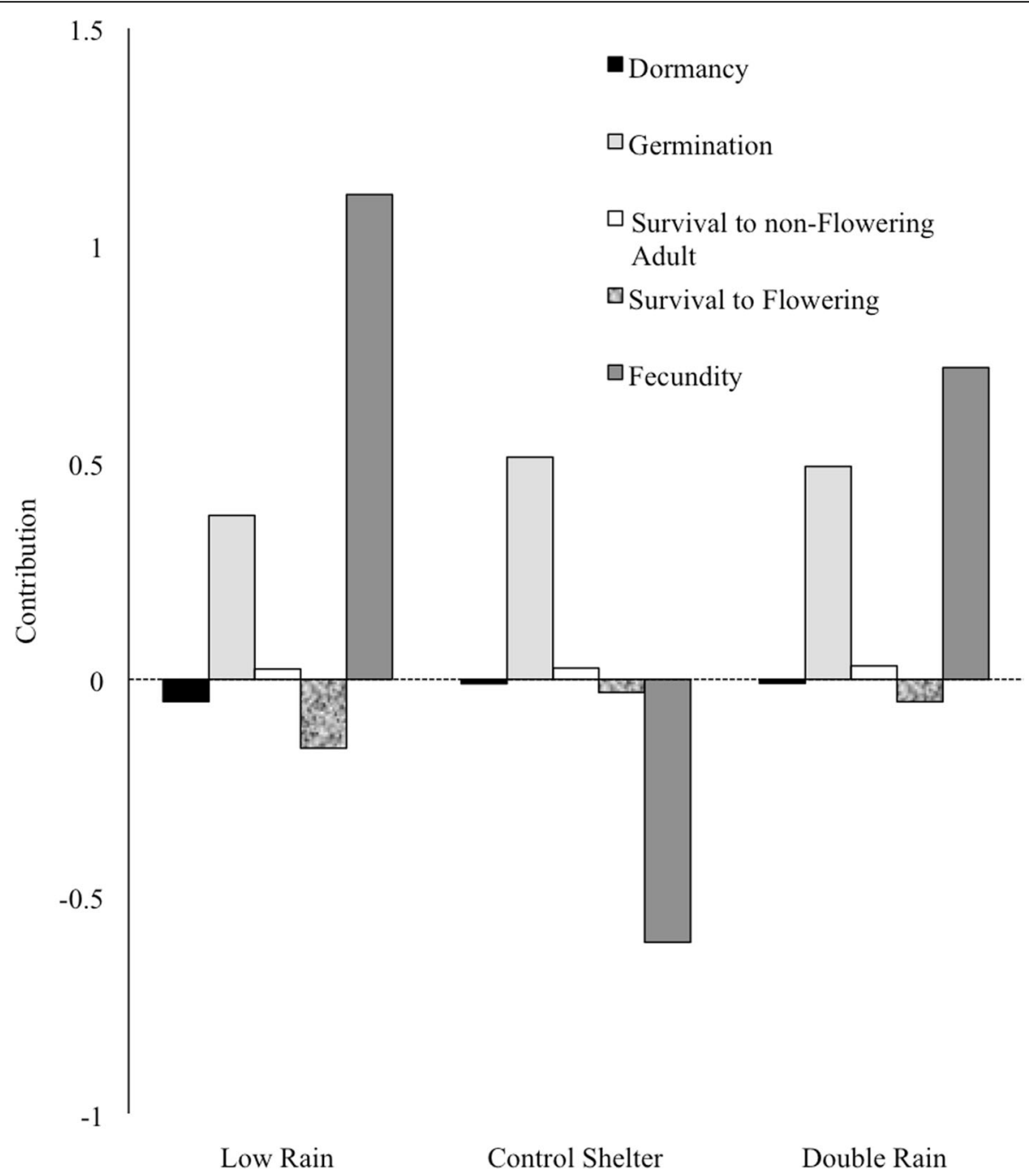

Fig. 4 Contributions from dormancy, germination, survival-to-non-flowering adult, survival-to-flowering, and fecundity vital rates of Raphanus, to differences between hybrid and wild biotype population growth rates $(\Delta \lambda)$, under three watering treatments [control shelter (CS), double rain (DR), low rain (LR)], grown in King City, ON, from 2012-2013. A 'contribution' from a vital rate is calculated as the 'difference' in corresponding matrix elements (wild - hybrid), weighted by its 'sensitivity' to describe how lambda changes with different vital rates

populations $[1,76]$. One significant shortcoming of fecundity studies to address this question is the potential for low correlation between the number of seeds produced and fitness ([77]; although this is more common in perennial plants; [78]). In contrast, demographic estimates can account for both multi-generational survival and reproduction [37]. Certainly, in our study, although fecundity was the largest influence on population growth, differences in survival also played an important role in the differences in growth rate of these new populations and some risk assessment literature advocates their use $[2,79]$. Here, we propose a second way they can be useful as a predictive, risk assessment tool. Selection estimates derived from sensitivity analyses can clearly be used to predict whether crop-derived demographic traits (e.g., loss of dormancy, proportion of the population that transition from vegetative rosette to flowering, given that flowering is delayed in crop populations) will persist within weed populations. Based on our results, we predict that selection will favor loss of dormancy in crop-wild hybrid populations (i.e., selection for the crop-derived trait) and the delayed flowering that reduces the proportion of plants that survive to flower (i.e., selection against the crop-derived trait). Perhaps future demographic studies could modify the frequency of these traits within experimental populations to test whether the populations persist longer and grow faster (e.g., [4]). Alternatively, individual-based models, which characterize genotypes into groups of demographic strategies [80], could be used to compare the consequences of demographic trait variation in frequencies of possessing crop and wild traits. 


\section{Conclusion}

Our goal was to develop a quantitative understanding of the selection pressures experienced by weedy Raphanus and to ultimately develop predictions about the direction and pace of evolution under changing moisture conditions. Although field studies of selection in genetically diverse experimental populations growing under natural and manipulated conditions are transforming our understanding of selection dynamics [81, 82], few studies have employed a cumulative estimate of fitness and sensitivity analysis to estimate hybrid population growth [e.g., 59] or have addressed the specific issue of selection in weedy or invasive populations [9, 56-58]. This work reveals the context-dependency of the selective advantage of domesticated traits to the long-term population dynamics of weedy Raphanus populations.

\section{Acknowledgements}

We thank G. Blakelock, N. Pirimova, R. Parker, R. Ata, P. Chiranji, M. Bhundari, S. Farhoomand, M. Loganathan, A. Lulek, N. Makeen, H. Siddiqui, P. Utomi, A. Weis and staff at University of Toronto Koffler Scientific Reserve for logistical support. J. Conner kindly provided wild seeds from New York and A. Snow provided crop seeds. R. Parker, M. Woods, A. Weis, J. Koprivnikar, A. Laursen provided helpful comments on the manuscript and M. Miriti consulted on MATLAB analyses. Funds from Shell Center for Sustainability (to K.D. Whitney), Rice University (to LGC), Ohio State University (to KLM), NSERC Discovery grant (\#402305-2011 to LGC), and Ryerson University (to LGC) supported this work.

\section{Funding}

Funding was provided by Ryerson University, Shell Sustainability Grant at Rice University, and the Natural Sciences and Engineering Research Council of Canada (\#402325-2011 to LGC).

\section{Availability of data and materials}

The data set supporting the results of this article is available in the Dryad repository, http://dx.doi.org/10.5061/dryad.rp895

\section{Authors' contributions}

LGC and ZT designed research; ZT and AK performed the field work, ZT, AK and LGC performed data analysis; ZT and LGC wrote the paper. All authors have read and approved the final version of the manuscript.

\section{Competing interests}

The authors declare that they have no competing interests.

\section{Consent for publication}

Not applicable.

\section{Ethics approval and consent to participate}

Not applicable.

\author{
Author details \\ ${ }^{1}$ Department of Chemistry and Biology, Ryerson University, 350 Victoria \\ Street, Toronto, ON M5B 2K3, Canada. ${ }^{2}$ Current Address: Department of \\ Integrative Biology, University of Guelph, 50 Stone Road East, Guelph, ON \\ N1G 2W1, Canada. ${ }^{3}$ Current Address: Department of Physical and \\ Environmental Sciences, University of Toronto Scarborough, 1265 Military \\ Trail, Toronto, ON M1C 1A4, Canada.
}

Received: 20 April 2016 Accepted: 20 November 2016 Published online: 07 December 2016

\section{References}

1. Ellstrand NC, Meirmans P, Rong J, Bartsch D, Ghosh A, Dejong TJ, et al. Introgression of crop alleles into wild or weedy populations. Annu Rev Ecol Syst. 2014;44:325-45.

2. Hooftman DAP, Oostermeijer JGB, Jacobs MMJ, den Nijs HCM. Demographic vital rates determine the performance advantage of crop-wild hybrids in lettuce. J Appl Ecol. 2005;42(6):1086-95.

3. Campbell LG, Snow AA, Ridley CE. Weed evolution after crop gene introgression: greater survival and fecundity of hybrids in a new environment. Ecol Lett. 2006;9(11):1198-209.

4. Campbell LG, Teitel Z, Miriti MN. Contemporary evolution and the dynamics of invasion in crop-wild hybrids with heritable variation for two weedy life histories. Evol Appl. 2016;9(5):697-708.

5. Rieseberg LH, Wendel JF. Introgression and its consequences in plants. In: Harrison RG, editor. hybrid zones and the evolutionary process. Oxford: Oxford University Press; 1993

6. Lewontin RC, Birch LC. Hybridization as a source of variation for adaptation to new environments. Evolution. 1966;20(3):315-36.

7. Hauser TP, Shaw RG, Ostergard $H$. Fitness of $F_{1}$ hybrids between weedy Brassica rapa and oilseed rape (B. napus). Heredity. 1998:81(4):429-35.

8. Snow AA, Moran-Palma P, Rieseberg LH, Wszelaki A, Seiler GJ. Fecundity, phenology, and seed dormancy of $F_{1}$ wild-crop hybrids in sunflower (Helianthus annuus, Asteraceae). Am J Bot. 1998;85(6):794-801.

9. Campbell LG, Snow AA, Sweeney PM. When divergent life histories hybridize: insights into adaptive life-history traits in an annual weed. New Phytol. 2009;184(4):806-18.

10. Bartsch D, Brand U, Morak C, Pohl-Orf M, Schuphan I, Ellstrand NC. Biosafety of hybrids between transgenic virus-resistant sugar beet and swiss chard. Ecol Appl. 2001;11(1):142-7.

11. Massinga RA, Al-Khatib K, St Amand P, Miller JF. Gene flow from imidazolinone-resistant domesticated sunflower to wild relatives. Weed Sci. 2003;51(6):854-62

12. Mercer $\mathrm{KL}$, Andow DA, Wyse DL, Shaw RG. Stress and domestication traits increase the relative fitness of crop-wild hybrids in sunflower. Ecol Lett. 2007;10(5):383-93.

13. Hovick SM, Campbell LG, Snow AA, Whitney KD. Hybridization alters early life-history traits and increases plant colonization success in a novel region. Am Nat. 2012;179(2):192-203.

14. Baucom RS, Mauricio R. The evolution of novel herbicide tolerance in a noxious weed: the geographic mosaic of selection. Evol Ecol. 2008;22(1):85-101.

15. Uwimana B, Smulders MJM, Hooftman DAP, Hartman $Y$, van Tienderen $\mathrm{PH}$, Jansen J, et al. Hybridization between crops and wild relatives: the contribution of cultivated lettuce to the vigour of crop-wild hybrids under drought, salinity and nutrient deficiency conditions. Theor Appl Genet. 2012;125(6):1097-111.

16. Cruzan MB, Arnold ML. Ecological and genetic associations in an iris hybrid zone. Evolution. 1993:47(5):1432-45.

17. Morris WF, Pfister CA, Tuljapurkar S, Haridas CV, Boggs CL, Boyce MS, et al. Longevity can buffer plant and animal populations against changing climatic variability. Ecology. 2008;89(1):19-25.

18. Wade MJ, Kalisz S. The causes of natural selection. Evolution. 1990;44(8):1947-55.

19. Etterson JR. Evolutionary potential of Chamaecrista fasciculata in relation to climate change. I. Clinal patterns of selection along an environmental gradient in the Great Plains. Evolution. 2004;58(7):1446-58.

20. Reznick DN, Bryga H. Life-history evolution in guppies (Poecilia reticulata): 1. Phenotypic and genetic changes in an introduction experiment. Evolution. 1987;41(6):1370-85.

21. Grant PR, Grant BR. Unpredictable evolution in a 30-year study of Darwin's finches. Science. 2002:296(5568):707-11.

22. Alberto FJ, Aitken SN, Alía R, González-Martínez SC, Hänninen H, Kremmer A et al. Potential for evolutionary responses to climate change-evidence from tree populations. Glob Change Biol. 2013;19(6):1645-61.

23. Heschel MS, Donohue K, Hausmann N, Schmitt J. Population differentiation and natural selection for water-use efficiency in Impatiens capensis. Int J Plant Sci. 2002;163(6):907-12.

24. Zangerl AR, Bazzaz FA. Effects of short-term selection along environmental gradients on variation in populations of Amaranthus retroflexus and Abutilon theophrasti. Ecology. 1984;65(1):207-17. 
25. Martin $B$, Thorstenson YR. Stable carbon isotope composition $\left(\delta^{13} \mathrm{C}\right)$, water use efficiency, and biomass productivity of Lycopersicon esculentum, Lycopersicon pennellii, and the $F_{1}$ hybrid. Plant Physiol. 1988;88(1):213-7.

26. Owart BR, Corbi J, Burke JM, Dechaine JM. Selection on crop-derived traits and QTL in sunflower (Helianthus annuus) crop-wild hybrids under water stress. PLoS One. 2014;9:e102717.

27. Barnett TP, Adam JC, Lettenmaier DP. Potential impacts of a warming climate on water availability in snow-dominated regions. Nature. 2005;438:303-9.

28. O'Gorman PA, Schneider T. The physical basis for increases in precipitation extremes in simulations of 21st-century climate change. P Natl Acad Sci USA. 2009;106:14773-7.

29. Adler LS, Wikler K, Wyndham FS, Linder CR, Schmitt J. Potential for persistence of genes escaped from canola: germination cues in crop, wild, and crop-wild hybrid Brassica rapa. Funct Ecol. 1993;7(6):736-45.

30. Johnson WC, Jackson LE, Ochoa O, Van Wijk R, Peleman J, St Clair DA, Michelmore RW. Lettuce, a shallow-rooted crop, and Lactuca serriola, its wild progenitor, differ at QTL determining root architecture and deep soil water exploitation. Theor Appl Genet. 2000;101(7):1066-73.

31. Snow AA, Pilson D, Rieseberg LH, Paulsen MJ, Pleskac N, Reagon MR, et al. A bt transgene reduces herbivory and enhances fecundity in wild sunflowers. Ecol Appl. 2003;13(2):279-86.

32. Jarvis A, Lane A, Hijmans RJ. The effect of climate change on crop wild relatives. Agr Ecosyst Environ. 2008;126(1-2):13-23.

33. Cleland EE, Chuine I, Menzel A, Mooney HA, Schwartz MD. Shifting plant phenology in response to global change. Trends Ecol Evol. 2007;22(7):357-65

34. IPCC (Intergovernmental Panel on Climate Change). Managing the risks of extreme events and disasters to advance climate change adaptation. In: Field CB, Barros V, Stocker TF, Qin D, Dokken DJ, Ebi KL, et al., editors. Special report of the intergovernmental panel on climate change. Cambridge: Cambridge University Press; 2012.

35. Hails RS, Morley K. Genes invading new populations: a risk assessment perspective. Trends Ecol Evol. 2005;20(5):245-52.

36. Hooftman DAP, Bullock JM, Morley K, Lamb C, Hodgson DJ, Bell P, et al. Seed bank dynamics govern persistence of brassica hybrids in crop and natural habitats. Ann Bot-London. 2015;115(1):147-57.

37. Caswell H. Matrix population models. 2nd ed. Sunderland: Sinauer Press; 2001.

38. Campbell LG, Teitel Z, Miriti MN, Snow AA. Context-specific enhanced invasiveness of Raphanus crop-wild hybrids: a test for associations between greater fecundity and population growth. Can J Plant Sci. 2014;94(8):1315-24.

39. Bergelson J. Changes in fecundity do not predict invasiveness: a model study of transgenic plants. Ecology. 1994;75(1):249-52.

40. Bullock JM. Using population matrix models to target $\mathrm{GMO}$ risk assessment. Asp Appl Biol. 1999:53:205-12.

41. van Tienderen PH. Elasticities and the link between demographic and evolutionary dynamics. Ecology. 2000;81(3):666-79.

42. Darwin C, Wallace A. On the tendency of species to form varieties: and on the perpetuation of varieties and species by natural means of selection. As communicated by C. Lyell and J.D. Hooker. J Proc Linn Soc London, Zool. 1858;3:45-62.

43. Gould SJ. Wonderful life. New York: Norton Co., Inc; 1989.

44. Simpson GG. Tempo and mode in evolution. New York: Columbia University Press; 1944

45. Holt RD. Population dynamics and evolutionary processes: the manifold roles of habitat selection. Evol Ecol. 1987;1:331-47.

46. Lanfear R, Kokko H, Eyre-Walker A. Population size and the rate of evolution. Trends Ecol Evol. 2013;29(1):33-41.

47. Parker IM. Invasion dynamics of Cytisus scoparius: a matrix model approach. Ecol Appl. 2000;10(3):726-43.

48. Koop AL, Horvitz CC. Projection matrix analysis of the demography of an invasive, nonnative shrub (Ardisia elliptica). Ecology. 2005;86(10):2661-72.

49. Snow AA, Campbell LG. Can feral radishes become weeds? In: Gressel J, editor. Crop ferality and volunteerism. Boca Raton: CRC Press; 2005. p. 193-208.

50. Panetsos CA, Baker HG. The origin of variation in "wild" Raphanus sativus (Cruciferae) in California. Genetica. 1967;38(1):243-74.

51. Holm LG, Doll J, Holm E, Pancho J, Herberger J. World weeds: natural histories and distributions. New York: Wiley; 1997.

52. Campbell LG, Parker RJM, Blakelock G, Pirimova N, Mercer KL. Maternal environment influences propagule pressure of an invasive plant, Raphanus raphanistrum, (Brassicaceae). Int J Plant Sci. 2015;176:393-403.
53. Teitel Z, Laursen AE, Campbell LG. Germination rates of weedy radish populations (Raphanus spp.) altered by crop-wild hybridisation, not humanmediated changes to soil moisture. Weed Res. 2016;56(2):149-58.

54. Teitel Z, Klimowski A, Campbell LG (2016) Data from: Assessing the effects of hybridization and precipitation on invasive weed demography using strength of selection on vital rates. Dryad Digital Repository. http://dx.doi. org/10.5061/dryad.rp895.

55. Miriti MN, Wright SJ, Howe HF. The effects of neighbors on the demography of a dominant desert shrub (Ambrosia dumosa). Ecol Monogr. 2001;71(4):491-509.

56. Weinig C. Differing selection in alternative competitive environments: shade-avoidance and germination timing. Evolution. 2000;50(1):124-36.

57. O'Donnell KL, Pigliucci M. Selection dynamics in native and introduced Persicaria species. Int J Plant Sci. 2010;171(5):519-28.

58. Lambrinos JG. How interactions between ecology and evolution influence contemporary invasion dynamics. Ecology. 2004;85(8):2061-70.

59. Hooftman DAP, Gerard J, Oostermeijer B, Marquard E, den Nijs HCM. Modelling the consequences of crop-wild relative gene flow: a sensitivity analysis of the effects of outcrossing rates and hybrid vigour breakdown in Lactuca. J Appl Ecol. 2008;45(4):1094-103.

60. Lee CE. Evolutionary genetics of invasive species. Trends Ecol Evol. 2002; 17(8):386-91.

61. Seiler GJ. Utilization of wild sunflower species for the improvement of cultivated sunflower. Field Crops Res. 1992;30(3-4):195-230.

62. Lawson HM, Waister PD, Stephens RJ. Patterns of emergence of several important arable weed species. Weed Control in the Northern Environment; Proceedings of a Symposium held 1974, Edinburgh. British Crop Protection Monograph. 1974;9:121-35.

63. Boutin C, Harper JL. A comparative study of the population dynamics of 5 species of Veronica in natural habitats. J Ecol. 1991;79(1):199-221.

64. Mohler CL. Ecological bases for the cultural control of annual weeds. J Prod Agr. 1996;9(4):468-74.

65. Kingsolver JG, Pfennig DW. Patterns and power of phenotypic selection in nature. Bioscience. 2007;57(7):561-72.

66. Benton TG, Grant A. How to keep fit in the real world: elasticity analyses and selection pressures on life histories in a variable environment. Am Nat. 1996;147(1):115-39.

67. Grant A. Selection pressures on vital rates in density-dependent populations. P Roy Soc B-Biol Sci. 1997;264(1380):303-6.

68. Buckley YM, Briese DT, Rees M. Demography and management of the invasive plant species Hypericum perforatum. II. Construction and use of an individual-based model to predict population dynamics and the effects of management strategies. J Appl Ecol. 2003;40(3):494-507.

69. Neubert MG, Parker IM. Projecting rates of spread for invasive species. Risk Anal. 2004;24(4):817-31.

70. Caswell H. Prospective and retrospective perturbation analyses: their roles in conservation biology. Ecology. 2000;81(3):619-27.

71. Salguero-Gomez R, Jones OR, Archer CR, Buckley YM, Che-Castaldo J, Caswell $\mathrm{H}$, et al. The Compadre plant matrix database: an open online repository for plant demography. J Ecol. 2015;103(1):202-18.

72. Ridley CE, Ellstrand NC. Evolution of enhanced reproduction in the hybridderived invasive, California wild radish (Raphanus sativus). Biol Invas. 2009; 11(10):2251-64.

73. Petru M, Tielborger K, Belkin R, Sternberg M, Jeltsch F. Life history variation in an annual plant under two opposing environmental constraints along an aridity gradient. Ecography. 2006;29(1):66-74.

74. Lucas RW, Forseth IN, Casper BB. Using rainout shelters to evaluate climate change effects on the demography of Cryptantha flava. J Ecology. 2008; 96(3):514-22.

75. Richards CL, Bossdorf O, Muth NZ, Gurevitch J, Pigliucci M. Jack of all trades, master of some? On the role of phenotypic plasticity in plant invasions. Ecol Lett. 2006:9(8):981-93.

76. Snow AA, Andow DA, Gepts P, Hallerman EM, Power A, Tiedje JM, Wolfenbarger LL. Genetically engineered organisms and the environment: Current status and recommendations. Ecol Appl. 2004;15(2):377-404.

77. Weiner J, Campbell LG, Pino J, Echarte L. The allometry of reproduction within plant populations. J Ecol. 2009;97:1220-33.

78. Silvertown J, Franco M, Pisanty I, Mendoza A. Comparative plant demography-relative importance of life-cycle components to the finite rate of increase in woody and herbaceous perennials. J Ecol. 1993;81(3):465-76. 
79. Tidemann BD, Hall LM, Harker KN, Alexander BCS. Identifying critical control points in the wild oat (Avena fatua) life cycle and the potential effects of harvest weed-seed control. Weed Sci. 2016;64(3):463-73.

80. DeAngelis DL, Mooij WM. Individual-based modeling of ecological and evolutionary processes. Ann Rev Ecol Evol Syst. 2005;36:147-68.

81. Conner JK. Understanding natural selection: an approach integrating selection gradients, multiplicative fitness components, and path analysis. Ethol Ecol Evol. 1996;8(4):387-97.

82. Lexer C, Randell RA, Rieseberg LH. Experimental hybridization as a tool for studying selection in the wild. Ecology. 2003;84(7):1688-99.

Submit your next manuscript to BioMed Central and we will help you at every step:

- We accept pre-submission inquiries

- Our selector tool helps you to find the most relevant journal

- We provide round the clock customer support

- Convenient online submission

- Thorough peer review

- Inclusion in PubMed and all major indexing services

- Maximum visibility for your research

Submit your manuscript at www.biomedcentral.com/submit 